\title{
LETTER
}

\section{Inter-regional transfers for pandemic surges were associated with reduced mortality rates}

\author{
Antoine Guillon ${ }^{1}$ (D), Emeline Laurent ${ }^{2,3}$, Lucile Godillon², Antoine Kimmoun ${ }^{4}$ \\ and Leslie Grammatico-Guillon ${ }^{2,5,6^{*}}$
}

๑ 2021 Springer-Verlag GmbH Germany, part of Springer Nature

\section{Dear Editor,}

The spread of the coronavirus disease 2019 (COVID19) pandemic has shown important spatial heterogeneity of in-hospital COVID-19 cases and deaths between countries and regions. Across metropolitan France, the healthcare system has been overwhelmed by the pandemic surge unequally over the regions, leading to the inability to provide care in areas with outpaced resources $[1,2]$. In response, mass inter-regional transfers of critically ill patients have been organized. Distribution of evacuation and mutual-aid agreements were coordinated by Regional Health Authorities, and not as a typical day-to-day transfer system. Critical care transports were performed by specialized ground and aeromedical teams (including intensivists and emergency physicians). However, the evacuation of multiple critically ill patients raised important issues [3]. Overall, we do not know whether the mortality rates of transferred patients are closer to the ones observed in the sending regions, or conversely, in the host regions. The objective was to assess whether patients transferred from outpaced regions had better outcomes compared to patients with similar severity taken in charge in the regions with surges in patient volume.

We performed a cross-sectional study using data from the French hospital discharge database (HDD), exhaustive for all public and private hospitals. We included patients from the three metropolitan French regions that organized mass inter-regional transfers. Patients were included according to the following criteria: adults $(\geq 18$

\footnotetext{
*Correspondence: leslie.guillon@univ-tours.fr

2 Epidemiology Unit EpiDclic, Service of Public Health, Tours University Hospital, 2 Bd Tonnellé, 37044 Tours Cedex 9, France
}

Full author information is available at the end of the article years old), with invasive mechanical ventilation, admitted in intensive care unit (ICU) between 2020-03-01 and 2020-05-31, with ICD-10 diagnosis code of COVID-19. To identify whether inter-regional transfers were associated with the ICU case fatality, a multivariate logistic regression model was carried out, including variables with $p<0.2$ in bivariate analysis. A descending stepwise process was used to select the final model. The Supplement details the methods.

Among the 6160 patients included, ICU-to-ICU interregional transfers were realized for 400 patients $(6.5 \%)$ (Supplementary Fig. 1). Patients were less likely to be transferred if they had a higher Charlson comorbidity index or initial specific care supports such as prone position, renal replacement therapy, ECMO (Table 1 upper section). Age, sex, and SAPS II were not associated with the decision of transfer. Case fatality was $39.5 \%(2278 / 5760)$ for patients not transferred and $14.3 \%(57 / 400)$ for patients transferred. Among the factors significantly associated with case fatality, ICU-toICU inter-regional transfers were predictors of survival (adjusted OR: 0.26 [0.2-0.3], $p<0.0001$ ) after adjustment on comorbidities and severity (Table 1 lower section).

This study has limitations: (i) the study is from the "first wave", therapeutic approaches have evolved since; (ii) healthcare systems vary across countries; thus our results should be extrapolated with caution; (iii) the lack of granularity of the database could be a limiting factor, but conversely it is an exhaustive real-life record of all patients hospitalized without initial selection bias. 
Table 1 Factors associated with the decision of ICU-to-ICU inter-regional transfer of critically ill COVID-19 patients from French regions that organized mass interregional transfers and factors associated with case fatality in mechanically ventilated COVID-19 patients hospitalized in regions that organized mass inter-regional transfers (Bourgogne-FrancheComté, Grand Est, lle-de-France; March-May 2020)

\begin{tabular}{|c|c|c|c|c|c|c|}
\hline \multirow{3}{*}{$\begin{array}{l}\text { Factors associated with the decision of ICU-to-ICU } \\
\text { inter-regional transfer }\end{array}$} & \multicolumn{3}{|l|}{ Bivariate analysis } & \multicolumn{3}{|c|}{ Multivariate analysis $\left(n=6111^{a}\right)$} \\
\hline & TOTAL & Transfer & $p$ value & \multirow[t]{3}{*}{ Adjusted OR } & \multirow[t]{3}{*}{$\mathrm{Cl} 95$} & \multirow[t]{3}{*}{$p$ value } \\
\hline & $(n=6160-100 \%)$ & \multicolumn{2}{|c|}{$(n=400-6.5 \%)$} & & & \\
\hline & $N$ & $N$ & & & & \\
\hline
\end{tabular}

Age

\begin{tabular}{|c|c|c|c|c|c|c|c|}
\hline$<65$ years-old & 3236 & 216 & 6.7 & 0.54 & Ref & & \\
\hline$\geq 65$ years-old & 2924 & 184 & 6.3 & & 0.99 & {$[0.8-1.2]$} & 0.92 \\
\hline \multicolumn{8}{|l|}{ Sex } \\
\hline Male & 4515 & 294 & 6.5 & \multirow[t]{2}{*}{0.92} & Ref & & \\
\hline Female & 1645 & 106 & 6.4 & & 0.91 & {$[0.7-1.2]$} & 0.43 \\
\hline \multicolumn{8}{|l|}{ SAPS II } \\
\hline Mean & 43.5 & 42.0 & & \multicolumn{2}{|l|}{0.07} & & \\
\hline$<30$ & 1261 & 80 & 6.3 & 0.31 & Ref & & \\
\hline [30-40] & 1614 & 117 & 7.2 & & 1.19 & {$[0.9-1.6]$} & 0.27 \\
\hline$\geq 40$ & 3236 & 198 & 6.1 & & 1.03 & {$[0.8-1.4]$} & 0.81 \\
\hline \multicolumn{8}{|l|}{ Charlson Comorbidity Index } \\
\hline Mean [min-max] & $1.51[0-17]$ & \multicolumn{2}{|l|}{$0.75[0-6]$} & $<.0001$ & 0.73 & {$[0.7-0.8]$} & $<0.0001$ \\
\hline \multicolumn{8}{|l|}{ Specific care supports during the first stay } \\
\hline Central venous catheter & 4071 & 269 & 6.6 & 0.61 & - & & \\
\hline Continuous hemodynamic monitoring & 3770 & 275 & 7.3 & 0.001 & 1.75 & {$[1.4-2.2]$} & $<0.0001$ \\
\hline Vasoactive treatment $^{\mathrm{b}}$ & 4842 & 306 & 6.3 & 0.29 & - & & \\
\hline Non invasive ventilation / high flow oxygenotherapy & 2126 & 53 & 2.5 & $<0.0001$ & 0.29 & {$[0.2-0.4]$} & $<0.0001$ \\
\hline Invasive ventilation with prone position & 3282 & 151 & 4.6 & $<0.0001$ & 0.53 & {$[0.4-0.7]$} & $<0.0001$ \\
\hline Renal replacement therapy & 1104 & 22 & 2 & $<0.0001$ & 0.37 & {$[0.2-0.6]$} & $<0.0001$ \\
\hline ECMO & 277 & 3 & 1.1 & 0.002 & 0.20 & {$[0.1-0.6]$} & 0.006 \\
\hline \multirow[t]{4}{*}{ Factors associated with case fatality } & \multicolumn{4}{|l|}{ Bivariate analysis } & \multicolumn{3}{|c|}{ Multivariate analysis $\left(n=6,111^{a}\right)$} \\
\hline & \multirow{3}{*}{$\begin{array}{l}\text { TOTAL } \\
(n=6,160-100 \%) \\
N\end{array}$} & Death & & $p$ value & \multirow[t]{3}{*}{ Adjusted OR } & \multirow[t]{3}{*}{$\mathrm{Cl} 95$} & \multirow[t]{3}{*}{$p$ value } \\
\hline & & \multicolumn{3}{|c|}{$(n=2,335-37.9 \%)$} & & & \\
\hline & & $N$ & $\%$ & & & & \\
\hline
\end{tabular}

Age

\begin{tabular}{|c|c|c|c|c|c|c|c|}
\hline$<65$ years-old & 3236 & 906 & 28 & $<.0001$ & Ref & & \\
\hline $65-79$ years-old & 2705 & 1264 & 46.7 & & 2.49 & {$[2.2-2.8]$} & $<0.0001$ \\
\hline$\geq 80$ years-old & 219 & 165 & 75.3 & & 9.82 & {$[7-13.8]$} & $<0.0001$ \\
\hline \multicolumn{8}{|l|}{ Sex } \\
\hline Male & 4515 & 1757 & 38.9 & 0.007 & Ref & & \\
\hline Female & 1645 & 578 & 35.1 & & 1.15 & {$[1.0-1.3]$} & 0.03 \\
\hline \multicolumn{8}{|l|}{ SAPS II } \\
\hline Mean & 43.5 & 48.5 & & $<.0001$ & & & \\
\hline$<30$ & 1261 & 322 & 25.5 & $<.0001$ & Ref & & \\
\hline [30-40] & 1614 & 499 & 30.9 & & 1.05 & {$[0.9-1.3]$} & 0.64 \\
\hline$\geq 40$ & 3236 & 1495 & 46.2 & & 1.45 & {$[1.2-1.7]$} & $<0.0001$ \\
\hline \multicolumn{8}{|c|}{ Charlson Comorbidity Index } \\
\hline Mean [min-max] & $1.51[0-17]$ & $1.86[0-17]$ & & $<.0001$ & 1.09 & {$[1-1.1]$} & $<0.0001$ \\
\hline \multicolumn{8}{|l|}{ Specific care supports } \\
\hline Central venous catheter & 4265 & 1629 & 38.2 & 0.48 & - & & \\
\hline
\end{tabular}


Table 1 (continued)

\begin{tabular}{|c|c|c|c|c|c|c|c|}
\hline \multirow[t]{4}{*}{ Factors associated with case fatality } & \multicolumn{4}{|l|}{ Bivariate analysis } & \multicolumn{3}{|c|}{ Multivariate analysis $\left(n=6,111^{\mathrm{a}}\right)$} \\
\hline & \multirow{3}{*}{$\begin{array}{l}\text { TOTAL } \\
(n=6,160-100 \%) \\
N\end{array}$} & Death & & $p$ value & \multirow[t]{3}{*}{ Adjusted OR } & \multirow[t]{3}{*}{$\mathrm{Cl} 95$} & \multirow[t]{3}{*}{$p$ value } \\
\hline & & \multicolumn{3}{|c|}{$(n=2,335-37.9 \%)$} & & & \\
\hline & & $N$ & $\%$ & & & & \\
\hline Continuous hemodynamic monitoring & 4047 & 1519 & 37.5 & 0.41 & - & & \\
\hline Vasoactive treatment ${ }^{b}$ & 5080 & 2065 & 40.7 & $<0.0001$ & 1.48 & {$[1.3-1.8]$} & $<0.0001$ \\
\hline Non invasive ventilation / high flow oxygenotherapy & 2417 & 645 & 26.7 & $<0.0001$ & 0.44 & {$[0.4-0.5]$} & $<0.0001$ \\
\hline Invasive ventilation with prone position & 3538 & 1451 & 41 & $<0.0001$ & 1.38 & {$[1.2-1.6]$} & $<0.0001$ \\
\hline Renal replacement therapy & 1280 & 791 & 61.8 & $<0.0001$ & 3.09 & {$[2.7-3.6]$} & $<0.0001$ \\
\hline ECMO & 398 & 214 & 53.8 & $<0.0001$ & 2.35 & {$[1.9-3]$} & $<0.0001$ \\
\hline Inter-regional transfer & 400 & 57 & 14.3 & $<0.0001$ & 0.26 & {$[0.2-0.3]$} & $<0.0001$ \\
\hline
\end{tabular}

Adjusted $\mathrm{OR}<1$ refers to a decreased probability of inter-regional transfer

a Missing data SAPS II $n=49 / 6,160$

b Dobutamin, dopamin, epinephrine, norepinephrine

The regions overwhelmed by the pandemic surge have experienced an unprecedented shortage of ICU beds and qualified ICU staff. We demonstrated that the benefit to remove patients from areas with outpaced resources was greatly superior to the risk of complication due to long-distance transfers of ventilated patients. In conditions with regional planning and trained teams [3], ICU evacuations are an appropriate solution to help manage the spatial dimension of the pandemic.

\section{Supplementary Information}

The online version contains supplementary material available at https://doi. org/10.1007/s00134-021-06412-3.

\section{Abbreviations}

HDD: Hospital discharge database; ICU: Intensive care unit; SAPS II: Simplified Acute Physiology Score II; SD: Standard deviation.

\begin{abstract}
Author details
${ }^{1}$ Intensive Care Unit, Tours University Hospital, Research Center for Respiratory Diseases, INSERM U1100, University of Tours, Tours, France. ${ }^{2}$ Epidemiology Unit EpiDcliC, Service of Public Health, Tours University Hospital, 2 Bd Tonnellé, 37044 Tours Cedex 9, France. ${ }^{3}$ Research Unit EA7505 (Education Ethique Et Santé), University of Tours, Tours, France. ${ }^{4}$ Intensive Care Unit, Teaching Hospital of Nancy, University of Lorraine, INSERM U1116, Nancy, France. ${ }^{5}$ MAVIVH, INSERM U1259, Tours, France. ${ }^{6}$ University of Tours, Tours, France.
\end{abstract}

\section{Acknowledgements}

We thank all staffs of health care facilities who contributed to the Hospital Discharge Database implementation.

\section{Author contributions}

AG, LGG, LG, EL conceived and designed the study and were involved in drafting the manuscript. $L G$ performed the data retrieval and $L G, E L, A G$, and LGG performed the statistical analysis. LG, EL, AG, AK and LGG were involved in the interpretation of the data, in drafting the manuscript and made critical revisions to the discussion section. $\mathrm{LG}, \mathrm{EL}, \mathrm{AG}, \mathrm{AK}$, and $\mathrm{LGG}$ read and approved the final version to be published.

\section{Funding}

The authors declare that they have no sources of funding for the research.

\section{Availability of data and materials}

Restrictions apply to the availability of these data and so are not publicly available. However, data are available from the authors upon reasonable request and with the permission of the institution.

\section{Declarations}

\section{Conflicts of interest}

The authors declare that they have no conflict of interest.

\section{Ethics approval and consent to participate}

No nominative, sensitive or personal data of patients have been collected. Our study involved the reuse of already recorded and anonymized data. The study falls within the scope of the French Reference Methodology MR-005 (declaration $2205437 \vee 0$, august $22^{\text {nd }}, 2018$, subscripted by the Teaching Hospital of Tours), which requires neither information nor consent of the included individuals. This study was consequently registered with the French Data Protection Board (CNIL MR-005 number \#2018160620).

\section{Publisher's Note}

Springer Nature remains neutral with regard to jurisdictional claims in published maps and institutional affiliations.

Accepted: 9 April 2021

Published online: 15 May 2021

\section{References}

1. Rimmelé T, Pascal L, Polazzi S, Duclos A (2020) Organizational aspects of care associated with mortality in critically ill COVID-19 patients. Intensive Care Med. https://doi.org/10.1007/s00134-020-06249-2

2. Gaudart J, Landier J, Huiart L et al (2021) Factors associated with the spatial heterogeneity of the first wave of COVID-19 in France: a nationwide geo-epidemiological study. Lancet Public Health. https://doi.org/10. 1016/S2468-2667(21)00006-2

3. King MA, Niven AS, Beninati W et al (2014) Evacuation of the ICU: care of the critically ill and injured during pandemics and disasters: CHEST consensus statement. Chest 146:e44S-60S. https://doi.org/10.1378/chest. 14-0735 